\title{
Activation of epithelial proliferation induced by Eimeria acervulina infection in the duodenum may be associated with cholesterol metabolism
}

\author{
Lili Sun ${ }^{1}$, Haibo Dong ${ }^{1}$, Zhenchao Zhang ${ }^{2}$, Jie Liu ${ }^{1}$, Yun Hu${ }^{1}$, Yingdong Ni $^{1}$, Roland \\ Grossmann $^{3}$, Ruqian Zhao ${ }^{1}$ \\ ${ }^{1}$ Key Laboratory of Animal Physiology and Biochemistry, Ministry of Agriculture, Nanjing Agricultural University, Nanjing \\ 210095, China \\ ${ }^{2}$ Department of Veterinary Parasitic Disease, College of Veterinary Medicine, Nanjing Agricultural University, Nanjing 210095, China \\ ${ }^{3}$ Department of Functional Genomics and Bioregulation, Institute of Animal Genetics, FLI, Mariensee, Neustadt a Rbg, \\ Germany \\ Correspondence to: Yingdong Ni, e-mail: niyingdong@njau.edu.cn \\ Keywords: cell proliferation, cholesterol, coccidial infection, small intestine, miRNAs
}

Received: December 04, $2015 \quad$ Accepted: March 18, $2016 \quad$ Published: March 30, 2016

\section{ABSTRACT}

Cell proliferation in the intestine is commonly occurred during infection and inflammation to replace damaged enterocytes, and cholesterol as an essential constituent of cell membrane, is required for cell proliferation and growth. Here we found that coccidium-challenged (CC) chickens showed severe damages in intestinal structure, a significant increase of cell proliferation, and an activation of genes expression involved in the innate immune response. Compared to control (CON), CC chickens showed a marked decrease of cholesterol (Tch) level in the circulating system, but a significant increase in local duodenum epithelium. Increase of LDLR protein combined with a significant decrease of CYP27A1 protein expression in duodenum epithelium may contribute to intestinal cholesterol accumulation in CC chickens. Moreover, we found miRNAs targeting to CYP27A1 gene participating in post-transcriptional regulation. Hence, these results provide a new insight for the intervention of epithelial proliferation and cholesterol metabolism in the gastrointestinal tracts.

\section{INTRODUCTION}

The intestinal epithelium represents an exquisite model for the study of stem cell biology especially for investigating the relationship between inflammatory disorders and cell proliferation [1]. In small intestine, the duodenum is the main site containing more adenocarcinomas than jejunum and ileum combined possibly due to biliary or pancreatic effluents. Inflammation is generally considered as a beneficial response to host injury and infection in the intestine, and epithelial damage induces a localized repair response characterized by increased division of stem cells at the bottom of crypts to replace damaged epithelial cells [1]. However, chronic inflammation is increasingly recognized as a high risk factor for the development of disease and intestinal cancer [2]. Coccidiosis infection has been known as a good experimental model for the study of inflammatory response in small intestine [3], which can typically cause the intestinal epithelial sloughing, villus tip damage and enteritis [4]. In poultry industry, especially in intensive production systems, coccidiosis infection is one of the most commonly prevalent and economically important diseases caused by the intestinal protozoa Eimeria $[5,6]$.

Three species of Eimeria most commonly infect in poultry including Eimeria acervulina, Eimeria maxima and Eimeria tenella, which can lead to severe inflammation and damages to different parts of the intestine [7, 8]. It's well documented that the intestinal epithelium and local immune cells are important for protection against colitis and colitisassociated tumorigenesis at different stages of disease development. The pro-inflammatory cytokines such as interleukin-1 $\beta$ (IL-1 $\beta$ ) and interleukin-18 (IL-18) molecules induce inflammation and participate in epithelial repair and healing processes via recruitment and activation of immune cells [9]. Epithelial damage also induces a localized repair response characterized by enhancing division of stem cell at 
the base of crypts to replace the damaged epithelial cells [1]. Cytokines contribute to restoring epithelial barrier integrity by activating controlled proliferation of stem cells located in the crypt base and turnover of damaged epithelial cells, which prevents systemic dispersion of microflora and the induction of exaggerated inflammatory responses. However, chronic inflammatory diseases constitute major risk factors for the formation of neoplastic regions in the intestine particularly in the colon epithelium [10].

Cholesterol is an essential structural component of cell membranes for maintaining both the structural integrity and fluidity, and it also serves as a precursor for the biosynthesis of steroid hormones [11]. The supply of cholesterol is required for cell proliferation and renewal process. In vertebrates, the liver is considered as the major "control center" for maintenance of the systemic cholesterol homeostasis through de novo biosynthesis, clears cholesterol particles from plasma, and reverses cholesterol transport by conversion into bile acids [12]. During the last decade, however, an additional important role of the intestine in keeping cholesterol homeostasis has become apparent, which makes the intestine a potential target for investigating novel antiatherosclerotic strategies [13]. Cell synthesizes cholesterol through a complex process controlled by several factors and enzymes. With respect to enzymes, 3-hydroxy-3-methylglutaryl-CoA reductase (HMGCR) is the rate-limiting enzyme for cholesterol production [14]. On the other hand, cholesterol7-alphahydroxylase (CYP7A1) and sterol 27-hydroxylase (CYP27A1) mainly participate in the degradation of cholesterol via the classic bile acid biosynthetic pathway in the liver [6]. CYP27A1 can catalyze the oxidative cleavage of the steroid side chain and hydroxylation of cholesterol to 27-hydroxycholesterol (27-HOC) in the most tissues $[15,16]$. With respect to cholesterol uptake from the circulating system, LDL receptor (LDLR) and ApoA1 play a vital role in the biological process [17].

Increased proliferation of stem cells at the crypts has been found in the intestine epithelial damage induced by enteritis [1], however, the local cholesterol metabolism and the biologic mechanism have remained uncertain. We hypothesized that paralleled an increase of cell proliferation, local cholesterol metabolism in the intestine would be altered during epithelial cells renewal and turnover process induced by local infection. Therefore, the aim of this study was to evaluate and quantify the level of cholesterol in the circulation and local intestine, and to investigate the mechanism involved in this process.

\section{RESULTS}

\section{Alterations in epithelial damage and growth performance of $\mathrm{CON}$ and $\mathrm{CC}$ groups}

As shown in Table 1, coccidium-challenged (CC) chickens showed significantly higher lesion score in the duodenum tissue $(\mathrm{P}<0.01)$ compared to control $(\mathrm{CON})$. The number of oocysts in per gram feces (OPG) was higher in $\mathrm{CC}$ group ( $\mathrm{P}<0.01)$, which was absent in CON chickens. $\mathrm{CC}$ chickens showed a tendency to increase of food intake $(\mathrm{P}=$ $0.06)$ and feed conversion ratio $(\mathrm{FCR} ; \mathrm{P}=0.06)$ compared to CON. However, the mean body weight gain of CC group was less than $\mathrm{CON}$, yet did not reach the statistical significance $(\mathrm{P}>0.05)$. Moreover, there was no difference in liver and spleen weight or their relative weight to body weight between $\mathrm{CC}$ and CON chickens ( $\mathrm{P}>0.1)$ (Table 1).

\section{Histological characteristics}

HE staining showed that severe cellular damages, indentations and villus fracture were observed in the duodenum epithelium of CC chickens but not in CON. CC chickens had longer depth of crypts $(\mathrm{P}<0.01)$, but lower height of villus ( $\mathrm{P}=0.01)$ compared to $\mathrm{CON}$ counterparts; therefore, the ratio of the length of villus to crypt was significantly lower in $\mathrm{CC}$ birds than CON $(\mathrm{P}<0.01)$ (Figure 1). Moreover, the ultrastructure of the duodenum epithelium was detected by the transmission electron microscopic (TEM) method. CC birds displayed swollen villis, wider intercellular space and apparent nuclear breakdown, while the control chickens exhibited integrity and normal epithelia morphology and structure of duodenum (Figure 2).

\section{Plasma corticosterone concentration and Tch content in plasma and the duodenum mucosa}

The results showed that the level of total cholesterol (Tch) in plasma was significantly reduced by $\mathrm{CC}$ infection $(\mathrm{P}<0.01)$, while the content of Tch in local duodenum mucosa $(\mathrm{P}<0.05)$ was markedly increased in $\mathrm{CC}$ chickens compared to CON. Stress hormone corticosterone concentration in plasma was doubled in $\mathrm{CC}$ chickens and was significantly higher than that in $\mathrm{CON}(\mathrm{P}<0.05)$ (Figure 3$)$.

\section{Expression of detected innate immune genes in the duodenum epithelium}

The abundance of mRNAs encoding innate immune genes and genes involved in inflammatory response were greatly up-regulated in the duodenum epithelium of $\mathrm{CC}$ group compared to $\mathrm{CON}$ (Figure 4). Coccidiosis infection significantly increased TLR7 mRNA expression $(\mathrm{P}<$ $0.05)$ but not other TLRs, and enhanced interleukin- $1 \beta$ (IL-1 $\beta)(\mathrm{P}<0.05)$ and interferon $\gamma($ IFN- $\gamma)(\mathrm{P}<0.01)$ as well as inducible nitric oxide synthetase (iNOS) mRNA expression $(\mathrm{P}<0.01)$ in the duodenum epithelium.

\section{Changes of cell proliferation in the duodenum epithelium}

In order to elucidate whether the increase of cholesterol contributes to the division of stem cells in 
Table 1: Effect of Eimeria acervulina infection on the Growth performance

\begin{tabular}{lccc}
\hline & CON & Coccidium & P value \\
\hline BW,32d (g) & $1242.92 \pm 33.73$ & $1260.45 \pm 36.91$ & 0.73 \\
BW,39d (g) & $1727.14 \pm 58.18$ & $1767.33 \pm 50.48$ & 0.61 \\
BWG,32-39d (g) & $542.08 \pm 38.05$ & $502.73 \pm 53.42$ & 0.55 \\
FI,32-39d (g) & $1255.42 \pm 54.26$ & $1428.64 \pm 67.57$ & 0.06 \\
FCR,32-39d & $2.37 \pm 0.09$ & $2.75 \pm 0.17$ & 0.06 \\
Organs index & & & 0.26 \\
Liver (g) & $45.00 \pm 1.64$ & $47.67 \pm 1.61$ & 0.32 \\
Spleen (g) & $2.12 \pm 0.12$ & $1.95 \pm 0.12$ & 0.37 \\
Liver/BW \% & $2.61 \pm 0.07$ & $2.70 \pm 0.07$ & 0.94 \\
Spleen/BW \% & $0.12 \pm 0.01$ & $0.12 \pm 0.01$ & \\
Other index & & & 0.00 \\
Intestine lesion & $0.00 \pm 0.00$ & $1.47 \pm 0.17$ & $4.55 \pm 0.14$ \\
OPG (g) & $0.00 \pm 0.00$ & & 0 \\
\hline
\end{tabular}

Note: BW: body weight; BWG: body weight gain; FI: feed intake; FCR: feed conversation ratio; OPG: oocysts per gramme. Values are means \pm SEM. $n=14$ /group. Data are presented as means \pm SEM.

the duodenum epithelium, cell proliferative marker proliferating cell nuclear antigen (PCNA) mRNA and protein expression were detected by real-time PCR, western blot and immunohistochemical (IHC) analysis, respectively (Figure 5). Results showed that the abundance of PCNA mRNA $(\mathrm{P}<0.01)$ and protein $(\mathrm{P}<0.05)$ in the duodenum epithelium of $\mathrm{CC}$ group was significantly up-regulated compared to CON. The number of PCNA positive signal cells was also increased in the duodenum epithelium by coccidiosis-challenged.

\section{Alterations of mRNA, miRNA and protein expression of key factors involved in cholesterol metabolism in the duodenum epithelium of CON and CC groups}

There was no significant difference of genes expression including 3-hydroxy-3-methylglutaryl-CoA reductase (HMGCR), sterol regulatory element binding protein 1 and 2 (SREBP 1 and 2), sterol 27-hydroxylase (CYP27A1), low density lipoprotein receptor (LDLR), liver $x$ receptor alpha $(\mathrm{LXR} \alpha)$, apolipoproteins $\mathrm{A} 1$ and $\mathrm{B}$ (APOA1 and APOB) in the duodenum epithelium between two groups $(\mathrm{P}>0.05)$ (Figure 6). However, compared to $\mathrm{CON}$, the intensity of LDLR protein showed a tendency to increase in $\mathrm{CC}$ group $(\mathrm{P}=0.08)$, while the abundance of CYP27A1 protein was markedly decreased in the duodenum by coccidial-challenged $(\mathrm{P}<0.05)$ (Figure 7 ). The discrepancy between CYP27A1 mRNA and protein expression indicates the post-transcriptional regulation in the duodenum epithelium of CC group. Therefore, the level of microRNAs (miRNAs) specifically targeting to CYP27A1 mRNA was measured by real-time PCR. Among eleven miRNAs, four miRNAs including miR-1699, miR7477-5p, miR-1451-5p and miR-1608 expression were significantly increased in $\mathrm{CC}$ group compared to $\mathrm{CON}(\mathrm{P}<$ $0.05)$, which was consistent with the down-regulation of CYP27A1 protein expression (Figure 8).

\section{Functional validation of miR-1608 and miR-1699}

In order to investigate the functional validation of miR-1608 and miR-1699, a luciferase reporter system was conducted in this study. We found that ectopic expression of miR-1608 and miR-1699 significantly suppressed ( $\mathrm{p}<$ 0.05 ) the luciferase activity of HeLa cells co-transfected with the pmirGLO-CYP27A1-3'UTR dual-luciferase reporter plasmid at both 24 and $48 \mathrm{~h}$ (Figure 9).

\section{DISCUSSION}

Coccidial infection is a common event occurred in most mammals and avian species that typically leads to the intestine structural disruption and physiological dysfunction $[18,19]$. In this study, we also found severe structural damages in the duodenum of chickens infected with E. Acervulina as observed in the previous studies $[20,21]$. Local inflammation was also confirmed by the increase of TLR-7, the pro-inflammatory cytokine IL-1 $\beta$ and INF- $\gamma$ genes expression involved in the innate immune response. Moreover, the stress hormone corticosterone concentration in the circulating system was 
greatly increased in CC chickens indicating a high stress response induced by coccidial infection. Consequently, chickens infected with coccidial displayed lower growth performance with higher food intake but lower feed conversion efficiency as previous reports [5, 22].

The pro-inflammatory molecules induce inflammation and participate in epithelial repair and healing processes through recruitment and activation of immune cells in the intestine [9]. It's suggested that cytokines might contribute to restoring epithelial barrier integrity by inducing controlled proliferation of stem cells at the crypts during the acute phase of inflammation. However, during the chronic inflammation these molecules such us IL-18 and IFN- $\gamma$ might inhibit epithelial cell proliferation in neoplastic regions of the intestine [10]. In this study, an increase of cell proliferation was also observed in the crypt base of coccidia-infected chickens, which exhibited higher length of the crypts and higher PCNA signals in the duodenum epithelium. The abundance of PCNA signals represents the total mitotic cells present in the mucosa, including the epithelial population and lamina propria cells. As in mammals, the intestinal integrity in birds is

\section{A}

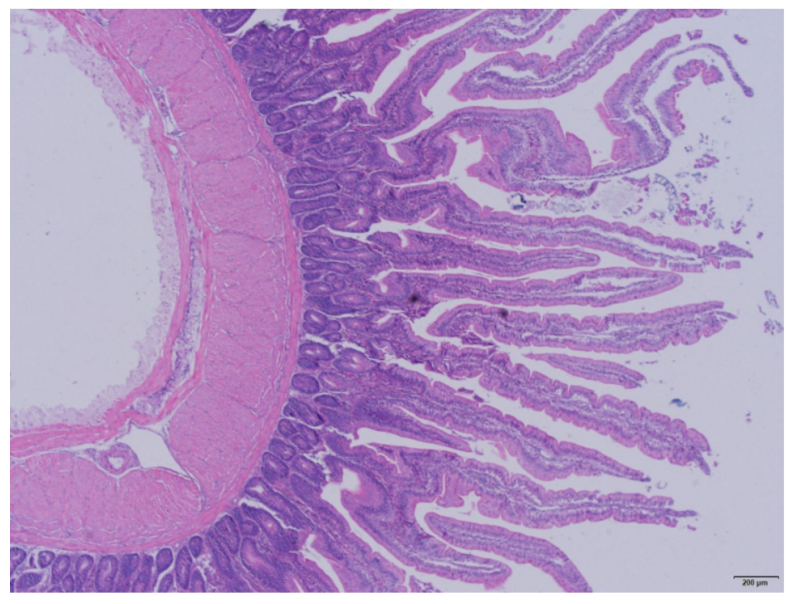

\section{C}

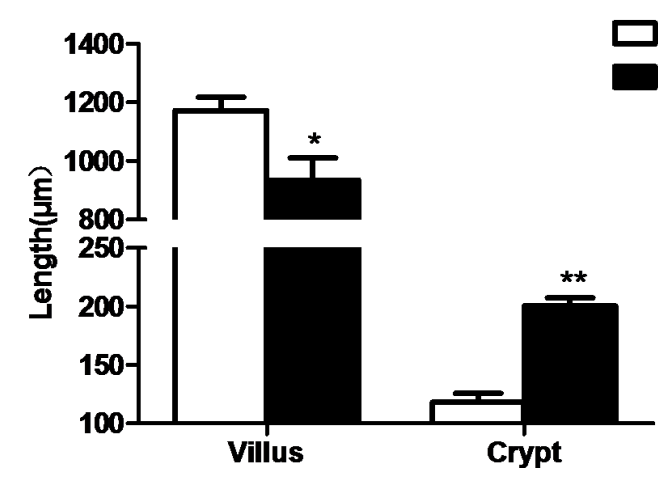

regulated tightly by many different signaling pathways which balance cell proliferation and differentiation along the crypt-villus axis [23, 24].

The availability of cholesterol is a prerequisite for cell proliferation and cellular growth, and change in membrane cholesterol content in the intestinal mucosa may affect membrane functions during development. It's documented that cholesterol is enriched in membrane microdomains perhaps mediating signal transduction [25]. A disruption in microdomain structures caused by reduced cholesterol content may prevent endocytosis of toxins or invasion by bacteria [26]. Evidences also suggest that local cholesterol synthesis in the gut is to support the rapid enterocyte proliferation [27]. Consistently, our results showed that local content of cholesterol was significantly increased in duodenum after coccidia-infection. On the contrary, the level of systemic cholesterol was greatly decreased in CC chickens, which might be due to the significant increase of corticosterone production. It's well known that cholesterol is the precursor for glucocorticoids and sexual hormones production in mammals and birds. The discrepancy between circulating and local cholesterol

B
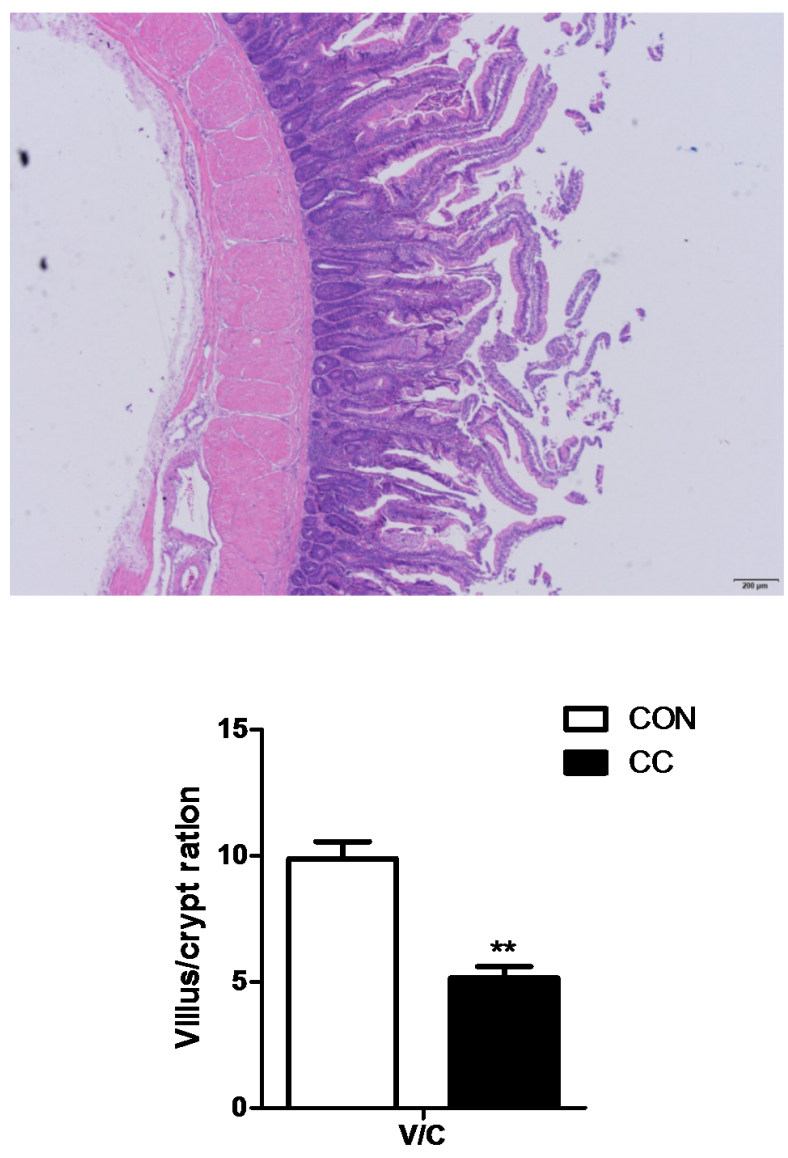

Figure 1: Comparisons of morphological of the duodenum mucosa between CON and CC chickens. Duodenum mucosa epithelium $(n=4)$ from each group were processed for morphological evaluation: duodenum section of CON group (A. scale bar $=200$ $\mu \mathrm{m})$; CC group (B. scale bar $=200 \mu \mathrm{m})$. The relative villus, crypt length and the ration of villus and crypt were measured $\mathbf{C}$. * Mean value was significantly different from that of the control group $(\mathrm{P}<0.05)$. 
content in intestine indicates that the alterations of local cholesterol metabolism are responsible for its accumulation in the duodenum epithelia in CC chickens.

The small intestine is quantitatively the most important organ involving in both cholesterol synthesis and LDL cholesterol uptake [27]. LDLR complexes are present in the cell surface mainly participating in an internalized process known as endocytosis. This process occurs in the majority of body cells including the epithelial cells in the small intestine. In this study, we found a moderate increase of LDLR protein in the duodenum epithelium of the coccidial-challenged chickens, which might contribute at least partially to the increase of local cholesterol content. Moreover, a significant decrease of CYP27A1 protein in the duodenum epithelium was observed in CC chickens compared to control. It's well known that cholesterol can be catabolized into bile acids through CYP27A1 and CYP7A1 in the liver [28-30].
The intestine is exposed to very high levels of dietary cholesterol, which may activate CYP27A1 in intestine to regulate intestinal cholesterol efflux [15]. The activation of pregnane $\mathrm{x}$ receptor (PXR) and CYP27A1 may be an adaptive response to a high-cholesterol diet to remove excessive un-esterified cholesterol in the intestine [31]. Taken together, our results suggest that the decrease of CYP27A1 protein combined with a moderate increase of LDLR may lead to intestinal cholesterol accumulation, and the latter is to support the epithelial cells proliferation during the inflammation induced by coccidial infection.

In the present study genes involved in cholesterol metabolism were not altered at the transcriptional level. The dissociation of mRNA and protein expression of CYP27A1 indicates the post-transcriptional regulation in the intestine. MicroRNAs are well known to participate in the post-transcriptional regulation through targeting mRNA degradation and/or translation repression [32].
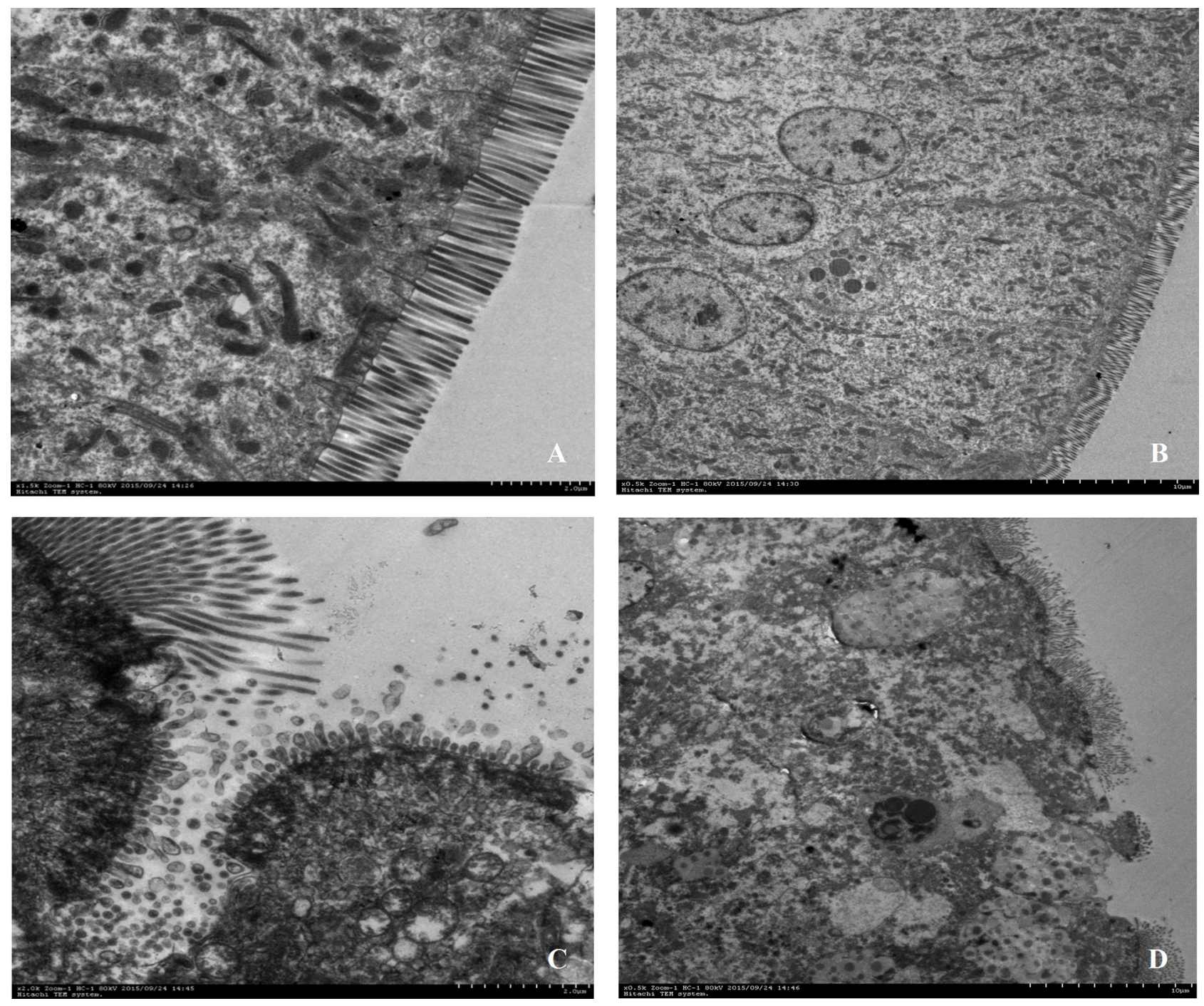

Figure 2: Comparisons of ultrastructure of the duodenum mucosa between CON and CC chickens. Duodenum mucosa epithelium $(\mathrm{n}=3)$ from each group were processed for ultrastructure evaluation: duodenum section of CON group A. and B. duodenum section of CC group C. and D. (A and C, Scale bar $=2 \mu \mathrm{m}$; B and D, Scale bar $=10 \mu \mathrm{m}$ ). 
A

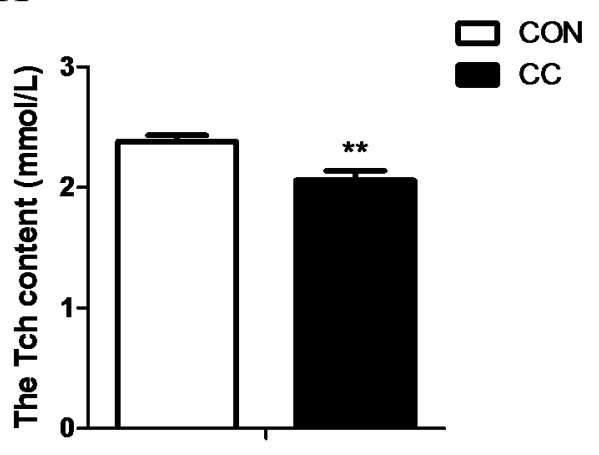

B

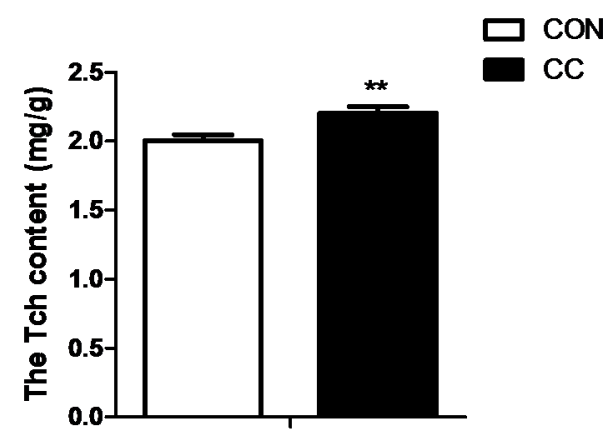

C

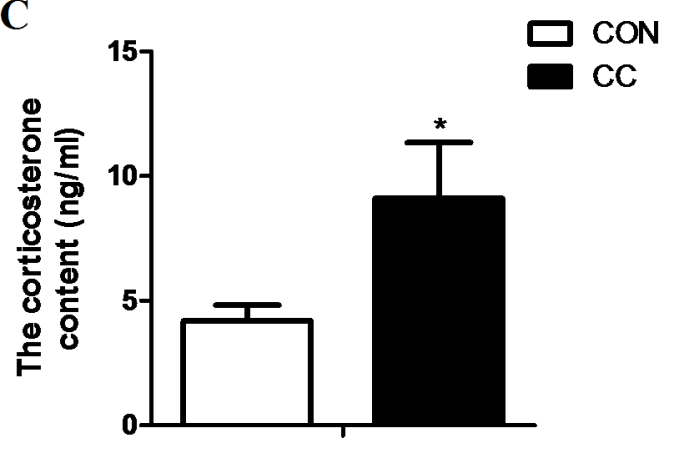

Figure 3: Comparisons of cholesterol content in plasma and the duodenum epithelium and plasma corticosterone between $\mathbf{C O N}$ and $\mathbf{C C}$ chickens. A. cholesterol content in serum. B. cholesterol content in the duodenum epithelium. $\mathbf{C}$. corticorsterone content in serum. Data are presented as means \{plus minus\} SEM. $\mathrm{n}=14$ /group. * Mean value was significantly different from that of the control group ( $\mathrm{P}<0.05)$.

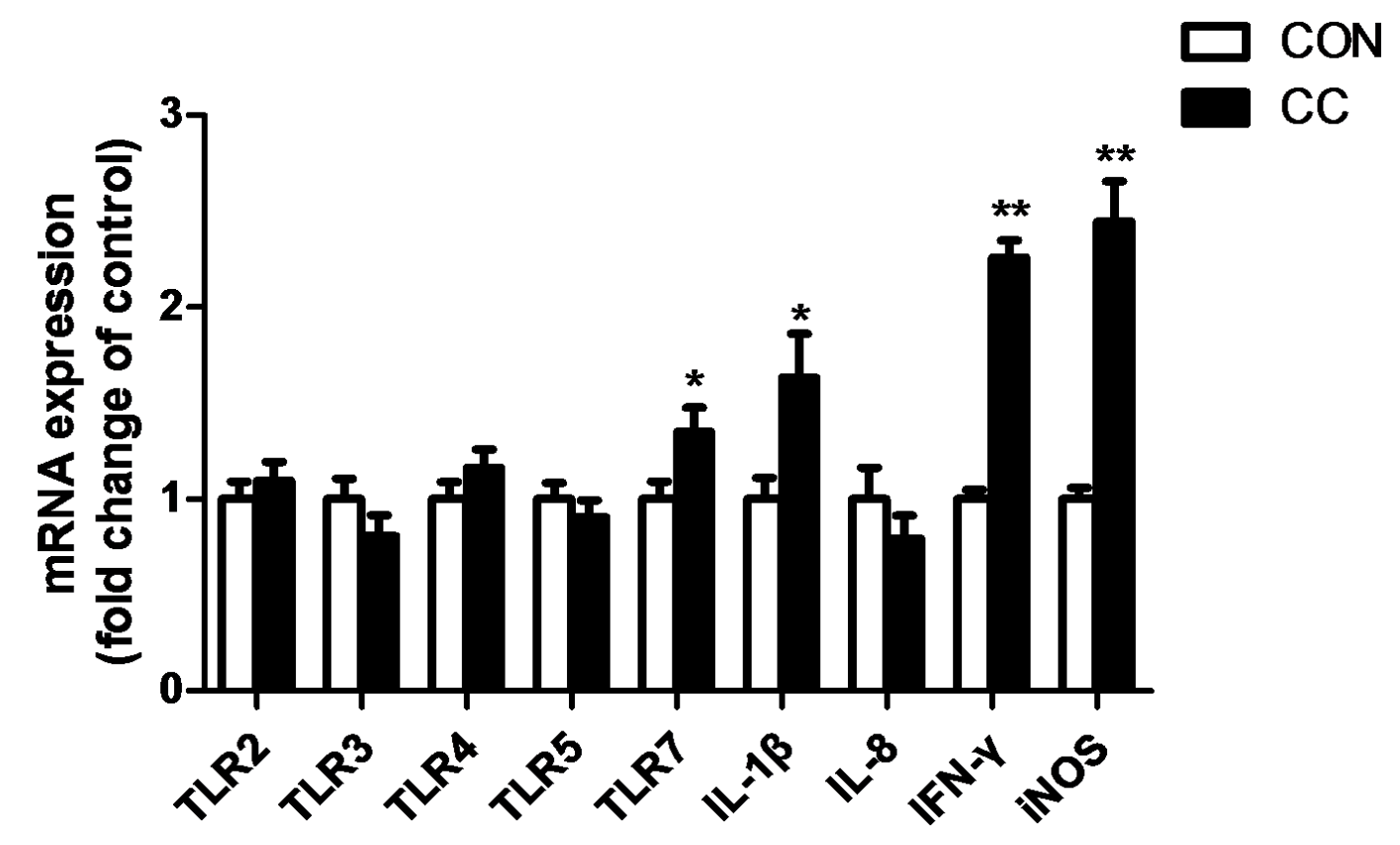

Figure 4: Comparisons of mRNA expression of inflammatory factors in the duodenum between CON and CC chickens. $\mathrm{Con}=$ control; $\mathrm{CC}=$ Coccidial challenge. Data are expressed by means \pm SEM. $\mathrm{n}=12$ /group. * Mean value was significantly different from that of the control group $(\mathrm{P}<0.05)$. 
When transcriptional regulation and miRNA-mediated translational repression are not synchronized, mRNA and protein levels can be uncoupled. In this study, the expression of four miRNAs targeting to CYP27A1 including miR-1699, miR-7477-5p, miR-1451-5p and miR-1608 was significantly increased in coccidia-infected chickens, which was associated with decreased protein content of CYP27A1 in the duodenum epithelium. To verify the targeting sites of miR-1608 and miR-1699 on 3'-UTR of CYP27A1 transcripts, we conducted luciferase reporter gene assay and confirmed that miR-1608 and miR-1699 inhibited luciferase activity through targeting 3'-UTR of CYP27A1. However, the nature behind the increase of miRNAs expression still needs further study.

It's very important to note that besides the similarity of histological features of intestine epithelia between avian and mammals, cell proliferation mainly occurs in the stem cell zone located in the intestinal crypt.

A

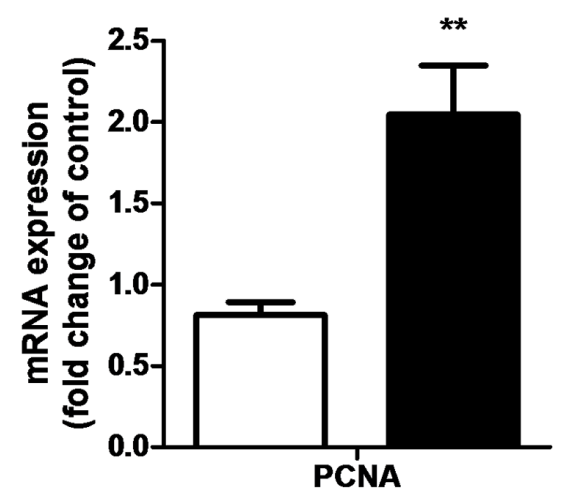

C

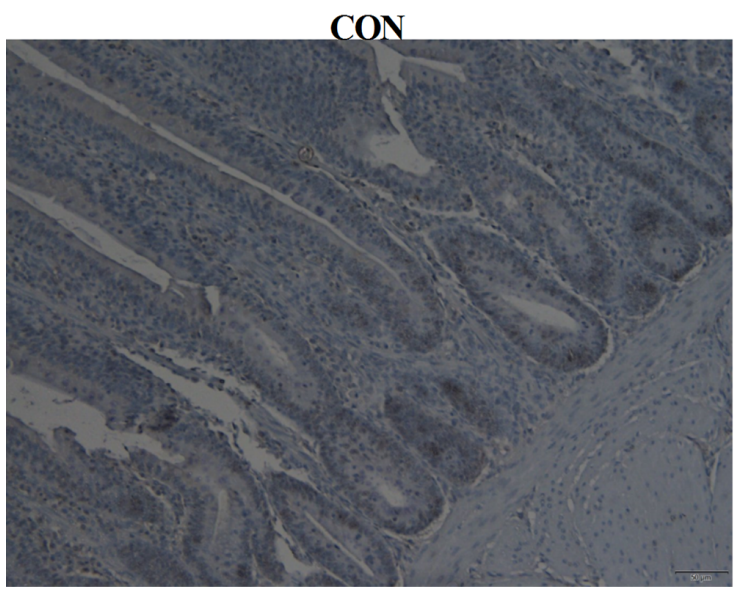

Intestinal homeostasis in chicken is also assumed to be similar to that of mammals [33]. Moreover, chickens are a good model for studying the disorders of cholesterol metabolism involved in the development of spontaneous arterial atherosclerotic lesions in human [34]. Therefore, it's reasonable to speculate that the conclusion derived from the current study has a potential impact on cancer patients in clinic.

In conclusion, we demonstrated here for the first time that E. acervulina infection induced intestinal inflammation, epithelial proliferation and the increase of cholesterol accumulation in duodenum epithelia. The increase of LDLR combined with the decrease of CYP27A1 protein may be at least partially responsible for local cholesterol accumulation, which contributes to the epithelial proliferation induced by infection. Moreover, the post-transcriptional regulation of miRNAs targeting to CYP27A1 was involved in this process. Taken together,
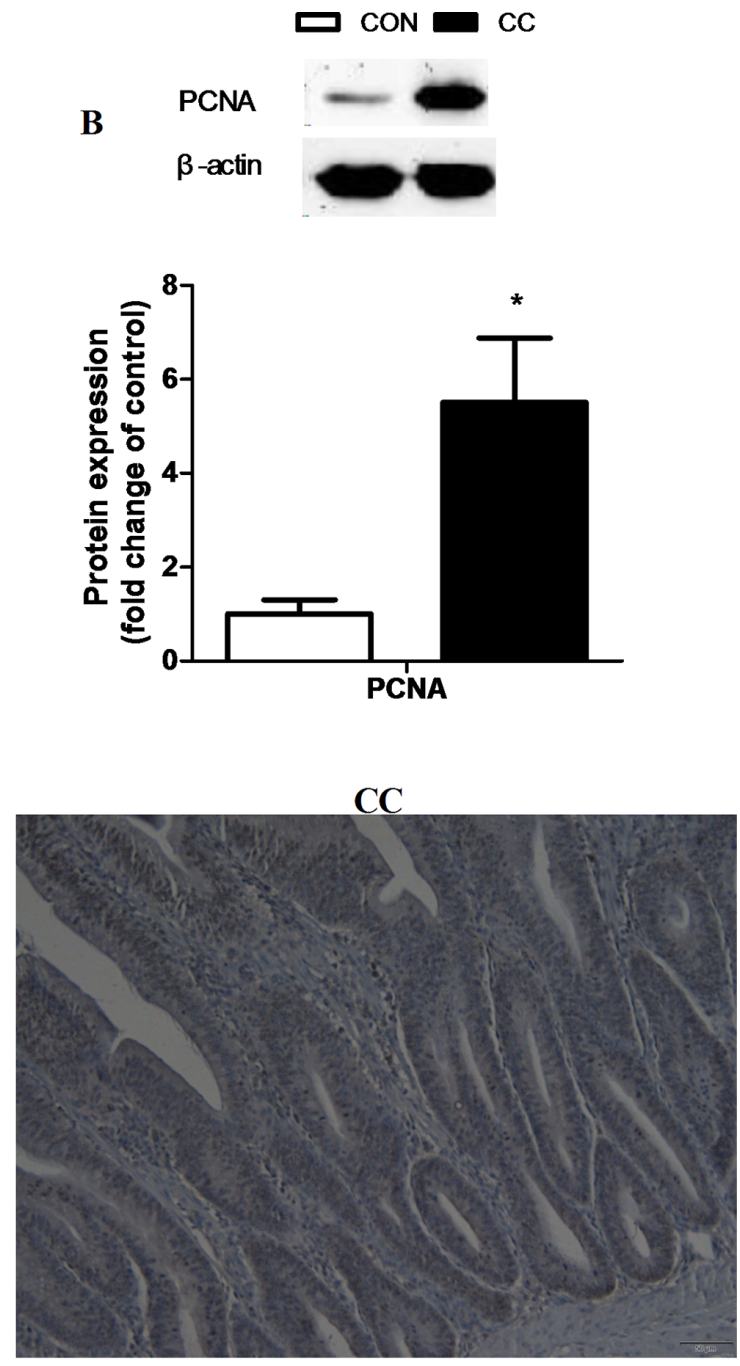

Figure 5: Effects of coccidial infection on the mRNA and protein levels of proliferating cell nuclear antigen (PCNA) in the duodenum mucosa. A. mRNA expression, $n=12$ /group. B. protein expression, $n=9$ /group. Con $=$ control; CC $=$ Coccidial challenge. Data are expressed by means \pm SEM. * Mean value was significantly different from that of the control group $(\mathrm{P}<0.05)$. Serial sections of chicken duodenum stained with PCNA IHC: duodenum section of the CON and CC group $(\mathbf{C}$. $\operatorname{scale~bar~}=50 \mu \mathrm{m})$. 


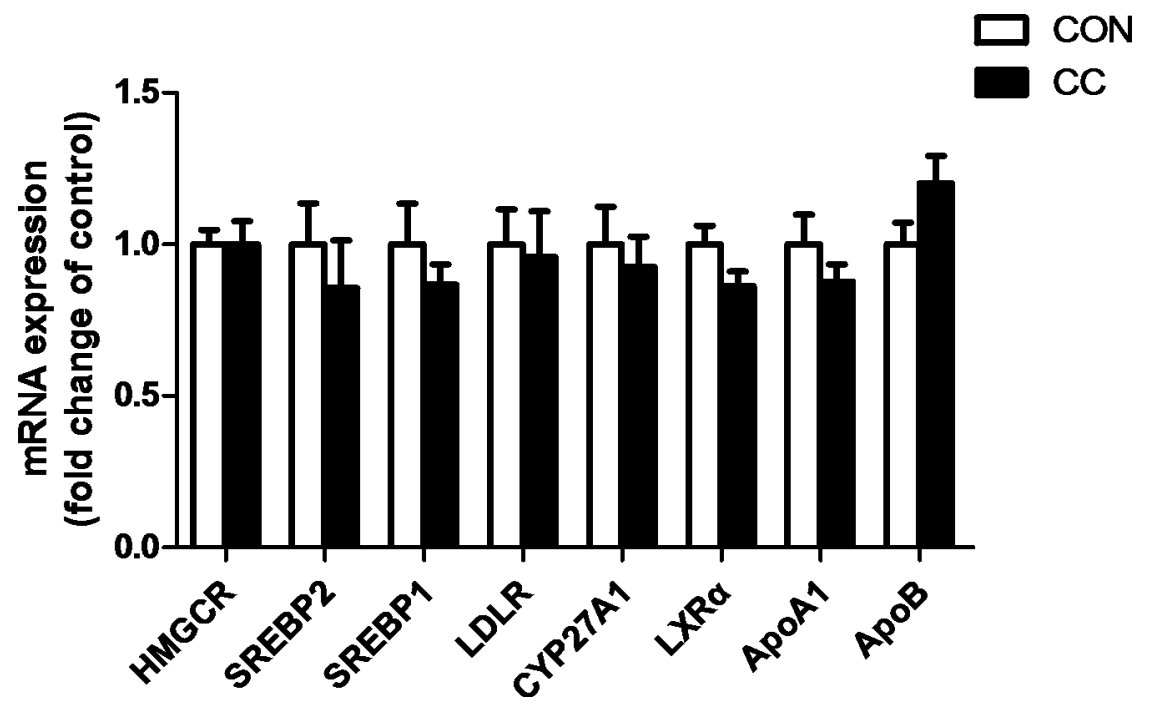

Figure 6: Effects of coccidial infection on genes expression involved in cholesterol metabolism in the duodenum mucosa. Con $=$ control; $\mathrm{CC}=$ Coccidial challenge. Data are expressed by means \pm SEM. $n=12$ /group.
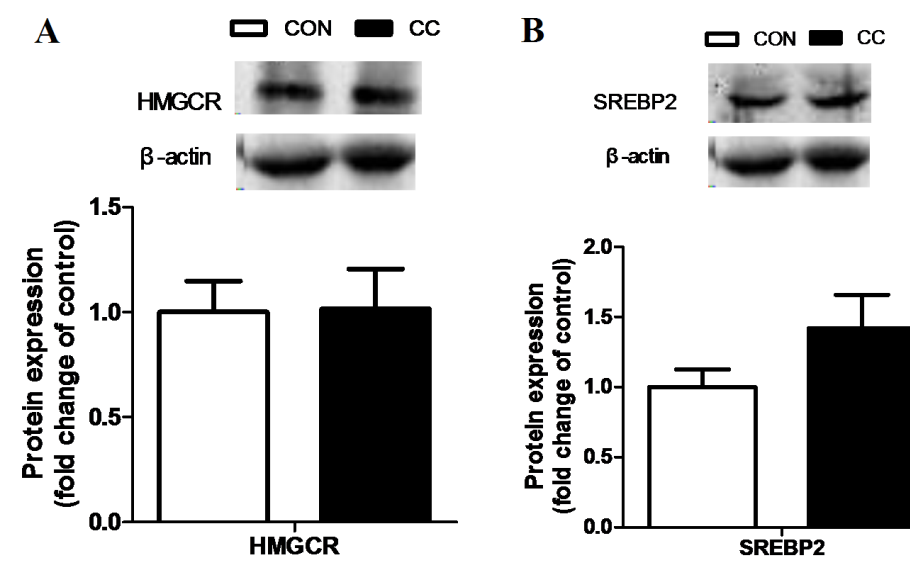

C
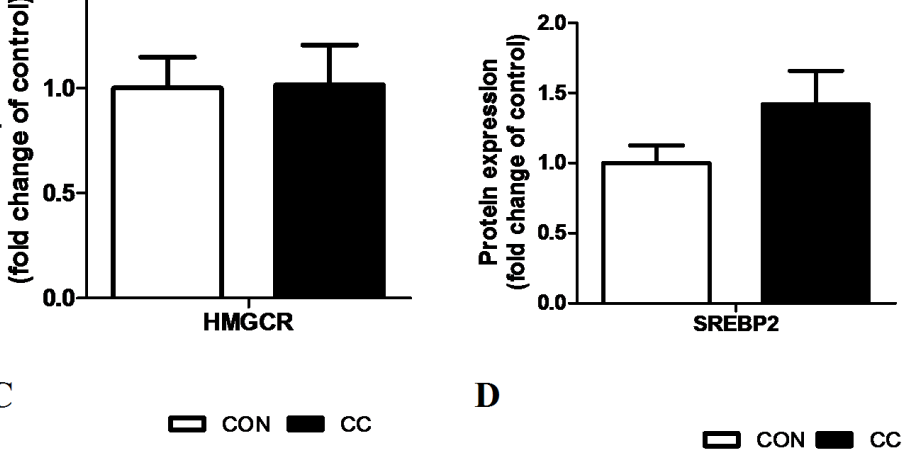

D
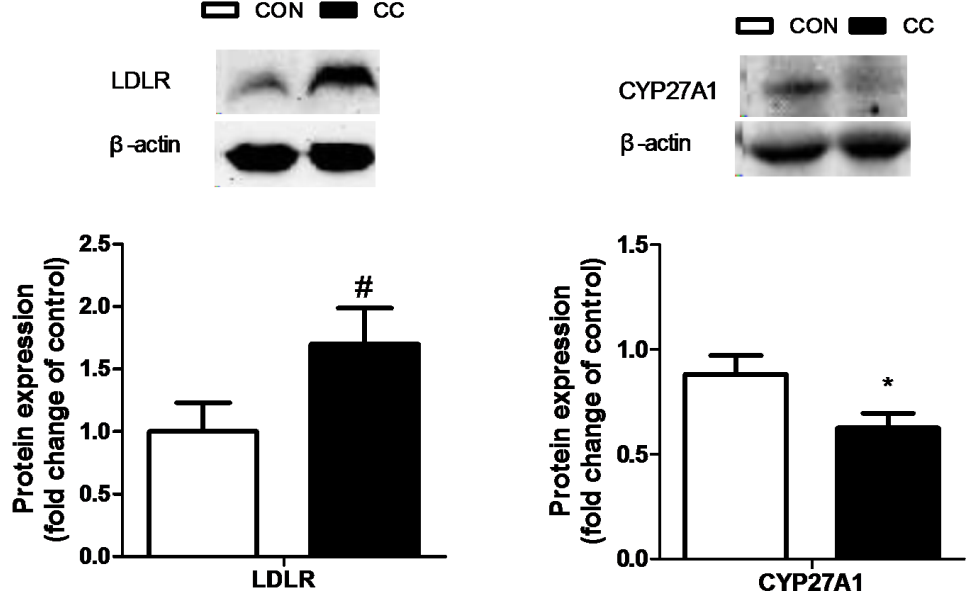

Figure 7: Effects of coccidial infection on proteins expression involved in cholesterol metabolism in the duodenum mucosa. Protein expression of the 3-hydroxy-3-methylglutaryl CoA reductase (HMGCR) A. the sterol regulatory element binding protein 2 (SREBP-2) B. the LDL receptor (LDLR) C. and the cholesterol-27a-hydroxylase (CYP27A1) D. Con = control; CC $=$ Coccidial challenge. Data are expressed by means \pm SEM. $n=9$ /group. * Mean value was significantly different from that of the control group $(\mathrm{P}<0.05)$. 


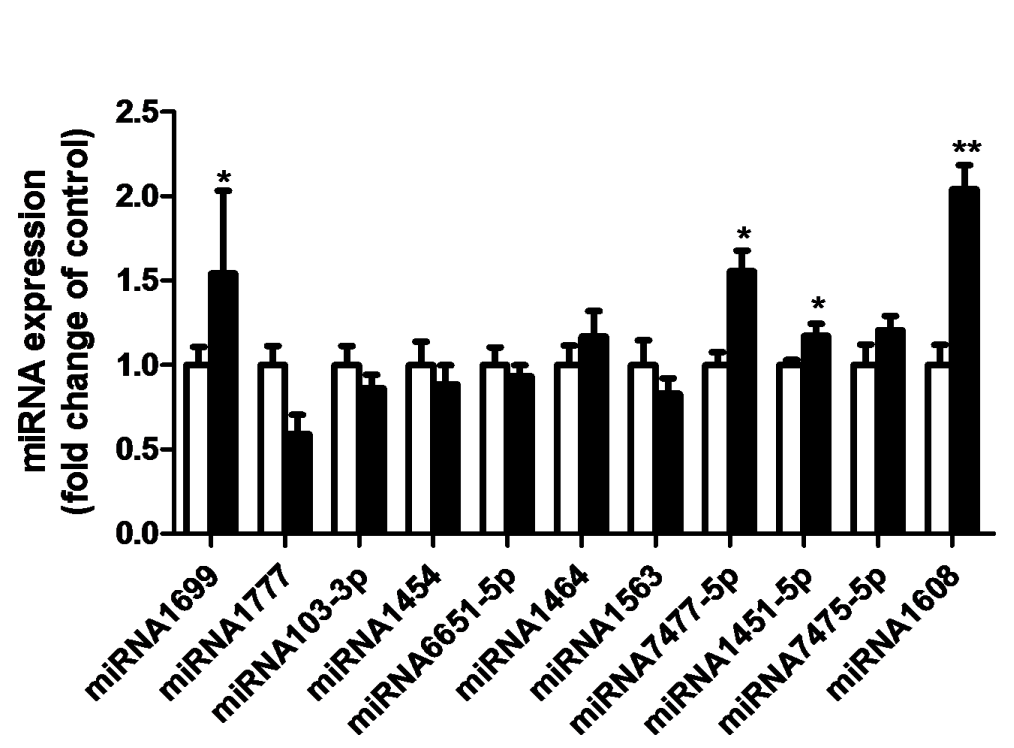

Figure 8: Effects of coccidial infection on miRNAs expression predicted to target cholesterol-27a-hydroxylase (CYP27A1) in the duodenum mucosa. $\mathrm{Con}=$ control; $\mathrm{CC}=$ Coccidial challenge. Data are expressed by means $\pm \mathrm{SEM} . \mathrm{n}=10$ /group. * Mean value was significantly different from that of the control group $(\mathrm{P}<0.05)$.
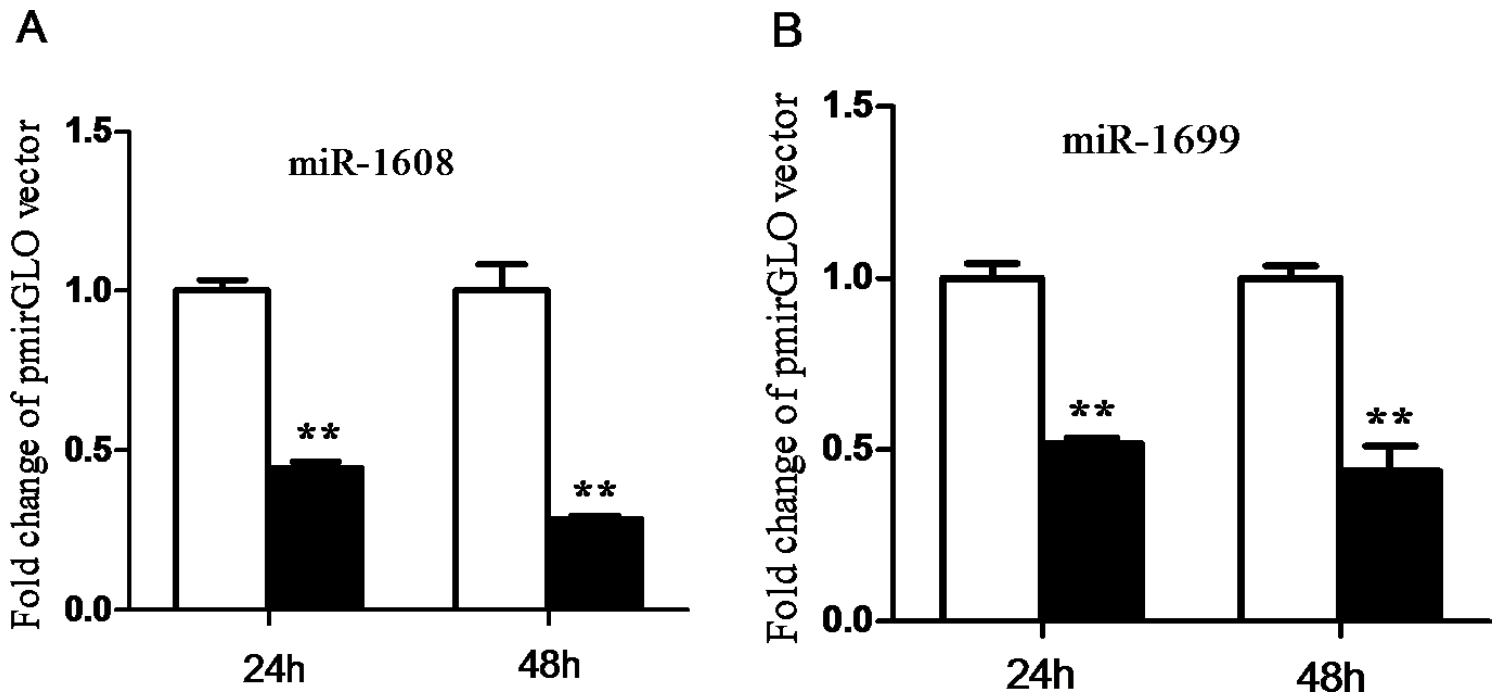

Figure 9: Validation of miR-1608 and miR-1699 targeting cholesterol-27a-hydroxylase (CYP27A1) 3'-UTR. A. $\square$,

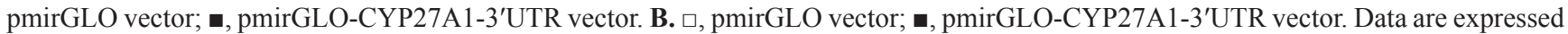
by means \pm SEM. $n=3$ /group. $*$ Mean value was significantly different from that of the control group $(\mathrm{P}<0.05)$.

our results provide a new insight for interventions of epithelial proliferation and cholesterol metabolism in the gastrointestinal tracts.

\section{MATERIALS AND METHODS}

\section{Animals and experimental design}

One hundred white-feather broilers (a local commercial breed) were purchased from a commercial hatchery, then were wing-banded and housed in the brood chamber. House temperature was maintained at $34 \pm 3^{\circ} \mathrm{C}$ in the first $3 \mathrm{~d}$, and decreased gradually to $21 \pm 3^{\circ} \mathrm{C}$ at $28 \mathrm{~d}$ of age. Starter crumble was provided from $1 \mathrm{~d}$ to $20 \mathrm{~d}$, and then finisher pellet was provided from $21 \mathrm{~d}$ to $39 \mathrm{~d}$. Continuous lighting was conducted during the first week, and the lighting time decreased gradually by $2 \mathrm{~h} /$ week to $18 \mathrm{~L}: 6 \mathrm{D}$ at $21 \mathrm{~d}$, and kept constant to $39 \mathrm{~d}$. On $32 \mathrm{~d}$, forty chickens with body weight close to the mean value in the whole group were caged and divided randomly into two groups. The remaining chickens were excluded from the study. All birds had free access to feed and water during the whole experimental period.

All animal procedures were approved by the Institutional Animal Care and Use Committee of Nanjing 
Agricultural University. The protocol of this study was reviewed and approved specifically, with the project number 2011CB100802. The slaughter and sampling procedures strictly followed the 'Guidelines on Ethical Treatment of Experimental Animals' (2006) no. 398 set by the Ministry of Science and Technology, China and the 'Regulation regarding the Management and Treatment of Experimental Animals' (2008) no. 45 set by the Jiangsu Provincial People's Government.

\section{Coccidial infection}

At $32 \mathrm{~d}$ of age, chickens in the coccidiosischallenged groups (CC) were challenged with $\mathrm{E}$. acervulina (200.000 oocysts/chicken, $\mathrm{n}=20)$ by oral administration and the unchallenged groups received the diluents as the control (CON). Body weight and feed intake (FI) per pen were recorded during the experiment.

\section{Blood and tissue sampling}

Chickens which were randomly selected from each replicate were weighed and killed by I.V. injection of pentobarbital $(30-40 \mathrm{mg} / \mathrm{kg}$ ) for tissue sampling on the 39 d. Blood samples were collected and then centrifuge ( 3500 rpm, $10 \mathrm{~min}$ ), the serum samples were stored at $-20^{\circ} \mathrm{C}$. The duodenum samples were collected into liquid nitrogen and then stored at $-70^{\circ} \mathrm{C}$ for subsequent RNA and protein extraction.

\section{Morphological analysis}

Specimens of the duodenum were prepared for histological examination by fixing in $4 \%$ formaldehydebuffered solution, embedding in paraffin, and sectioning $(5 \mu \mathrm{m})$. Specimens were examined for injury after hematoxylin and eosin (H\&E) staining as described by Makishima et al [35]. A total of 10 intact, well-oriented villus-crypt units were selected for each intestinal cross section. Villus height $(\mu \mathrm{m})$ was measured from the tip of the villus to the villus-crypt duodenum, and crypt depth was measured from the base upward to the region of transition between the crypt and villus.

Duodenum mucosa tissue samples were separated and fixed immediately with $2 \%$ glutaraldehyde, postfixed with $1 \%$ osmium tetroxide, and embedded in resin. Ultrathin sections were cut and stained with uranyl acetate and lead citrate. Epithelial tissues ultrastructure was determined with a transmission electron microscope (Hitachi H-7650, Hitachi Technologies, Tokyo, Japan).

\section{Immunohistochemical analysis (IHC)}

Immunohistochemical detection of proliferating cell nuclear antigen (PCNA) was performed on the duodenum sections as described previously [36]. In brief, representative paraffin sections $(5 \mu \mathrm{m})$ were subjected to immunohistochemistry staining. Tissue sections were quenched for endogenous peroxidase (0.01 M citrate buffer, $\mathrm{pH}$ 6.0) for $15 \mathrm{~min}$ in a water bath at $97^{\circ} \mathrm{C}$. Then, after incubation in $5 \% \mathrm{BSA}$ for 30 min at $37^{\circ} \mathrm{C}$, mouse MAb anti-PCNA (clone PC10; Santa) was applied to the sections at dilutions of 1:50 for overnight at $4^{\circ} \mathrm{C}$. After washing, slides were stained with a biotin-conjugated secondary antibody, followed by Streptavidin-Biotin complex (SA1051, Boster Company, Nanjing, China) for $30 \mathrm{~min}$ each at $37^{\circ} \mathrm{C}$. Staining was developed with DAB (AR1000, Boster Company, Nanjing, China), slides were counterstained with hematoxylin, dehydrated, and mounted. For negative control in the IHC procedures performed, PBS replaced the primary antibodies.

\section{Measurement of cholesterol in serum and tissue, corticosterone in serum}

One hundred milligram frozen duodenum was minced and homogenized by crushing equipment (MS100R; Japan) in $1 \mathrm{~mL}$ of ice-cold homogenization buffer RIPA (Pulilai, Beijing). The homogenate was centrifuged at $12,000 \mathrm{rpm}$ for $20 \mathrm{~min}$ at $4^{\circ} \mathrm{C}$ and then collected the supernatant. The cholesterol (CHOL) was measured using commercial kits (Pulilai, Beijing, China) according to the instruction provided by the manufacturer. The serum concentration of cholesterol (CHOL) were measured by automatic biochemical analyzer (Tokyo Japan, Hitachi7020) using commercial kits (Jiancheng Bioengineering Institute, Nanjing, China). CORT concentration in serum was measured using a commercial EIA kit (No. 500655, Cayman, USA) according to the instructions of the manufacturer.

\section{RNA, cDNA synthesis and real-time PCR}

Total RNA was extracted from duodenum samples with Trizol Reagent (Cat\#3101-100, Pufei, Shanghai, China). Concentration of the RNA was measured by NanoDrop ND-1000 Spectrophotometer (Thermo Fisher, USA). The ratios of absorption $(260 / 280 \mathrm{~nm})$ of all samples were between 1.9 and 2.0. The quality of RNA was assessed by electrophoresis on an agarose gel. 500 nanogram of total RNA was reverse-transcribed according to manufacturer's instructions (Vazyme Biotech, Nanjing, China). $2 \mathrm{uL}$ of diluted cDNA (1:25, vol/vol) was used for real-time PCR which was detected in Mx3000P (Stratagene, USA). TBP was used as a reference gene [37]. All the primers synthesized by Generay (Shanghai, China) were listed in Table 2. The method of $2^{-\Delta \Lambda} \mathrm{Ct}$ was used to analyze the real-time PCR results, and gene mRNA expression was showed as the fold change relative to the mean value of control group [28]. 
Table 2: Nucleotide sequences of specific primers

\begin{tabular}{|c|c|c|}
\hline Gene & Sequence $5^{\prime}-3^{\prime}$ & GenBank accession no. \\
\hline \multirow[t]{2}{*}{ TBP } & ATAGTGCCACAGCTACAGA & NM_205103.1 \\
\hline & GTACGTGGTTCTCTTATCCTC & \\
\hline \multirow[t]{2}{*}{ HMGCR } & TTGGATAGAGGGAAGAGGGAAG & NM_204485.1 \\
\hline & CCATAGCAGAACCCACCAGA & \\
\hline \multirow[t]{2}{*}{ SREBP1 } & CTACCGCTCATCCATCAACG & AY029224 \\
\hline & CTGCTTCAGCTTCTGGTTGC & \\
\hline \multirow[t]{2}{*}{ SREBP2 } & CCCAGAACAGCAAGCAAGG & XM_416222 \\
\hline & GCGAGGACAGGAAAGAGAGTG & \\
\hline \multirow[t]{2}{*}{ CYP27A1 } & AGGACTTTCGTCTGGCTCT & XM422056.4 \\
\hline & CTCCGCATCGGGTATTT & \\
\hline \multirow[t]{2}{*}{ LDLR } & CCACCATTTGGCAGAGGAA & NM_204452.1 \\
\hline & ACCGCAGTCAGACCAGAAGAG & \\
\hline \multirow[t]{2}{*}{ ApoA1 } & GTGACCCTCGCTGTGCTCTT & NM_205525.4 \\
\hline & CACTCAGCGTGTCCAGGTTGT & \\
\hline \multirow[t]{2}{*}{ ApoB } & GCATCTCTGCATCTCAGGAAAGA & NM_001044633.1 \\
\hline & GCAGGCTACAAACTAACAGATCCA & \\
\hline \multirow[t]{2}{*}{$\operatorname{LXR} \alpha$} & GCAACTACCTGGCTTCCGAGA & AJ507202.1 \\
\hline & CTGCTTTGGCGAAGTCATCCC & \\
\hline \multirow[t]{2}{*}{ PCNA } & TGAATGAGCCAGTCCAG & NM_204170.2 \\
\hline & AGTGTCCCATATCAGCAA & \\
\hline \multirow[t]{2}{*}{ TLR2 } & ATCCTGCTGGAGCCCATTCAGAG & NM_204278.1 \\
\hline & TTGCTCTTCATCAGGAGGCCACTC & \\
\hline \multirow[t]{2}{*}{ TLR3 } & TCAGTACATTTGTAACACCCCGCC & NM_001011691 \\
\hline & GGCGTCATAATCAAACACTCC & \\
\hline \multirow[t]{2}{*}{ TLR4 } & TGCCATCCCAACCCAACCACAG & AY064697 \\
\hline & ACACCCACTGAGCAGCACCAA & \\
\hline \multirow[t]{2}{*}{ TLR5 } & GCCTGGGGAAGAACATATCAAC & AJ626848 \\
\hline & GGCTTCTACACACCACCCATC & \\
\hline \multirow[t]{2}{*}{ TLR7 } & GGCTGTGAATGAATGGGTGA & NM_001011688 \\
\hline & GCTGAATGCTCTGGGAAAGG & \\
\hline \multirow[t]{2}{*}{ IL-1 $\beta$} & GTGAGGCTAACATTGCGCTGTA & Y15006.1 \\
\hline & TGTCCAGGCGGTAGAAGATGAAG & \\
\hline \multirow[t]{2}{*}{ IL-8 } & TCCTGGTTTCAGCTGCTCTGT & NM_205498 \\
\hline & CGCAGCTCATTCCCCATCT & \\
\hline \multirow[t]{2}{*}{ IFN- $\gamma$} & ACACTGACAAGTCAAAGCCGCACA & X99774 \\
\hline & AGTCGTTCATCGGGAGCTTGGC & \\
\hline \multirow[t]{2}{*}{ iNOS } & AATGCTGTGCCCATGGCAGTTTGCA & D85422 \\
\hline & CACCTCAAGGAGCATGTTGGCAACA & \\
\hline
\end{tabular}




\section{Protein extraction and western blot analysis}

One hundred milligram of frozen duodenum epithelium was minced and homogenized by crushing equipment (MS-100R; Japan) in $0.8 \mathrm{~mL}$ of ice-cold homogenization buffer RIPA containing the protease inhibitor cocktail Complete EDTA-free and PhosSTOP (Roche, Germany). The homogenate was centrifuged at $12,000 \mathrm{rpm}$ for $20 \mathrm{~min}$ at $4{ }^{\circ} \mathrm{C}$ and then collected the supernatant. Protein concentration was measured using a BCA Protein Assay kit (Pierce, Rockford, USA). 40 micrograms of protein extracted from each sample was loaded onto $10 \%$ SDA-PAGE gel. Into nitrocellulose membranes (Bio Trace, Pall Co., USA) and blocked for $2 \mathrm{~h}$ at room temperature, then were incubated with the following primary antibodies: HMGCR (BS6625, Bioworld Technology, 1:500), SREBP2 (SC-5603,Santa cruz; USA; 1:500), CYP27A1 (BS2192, Bioworld Technology, 1:500), LDLR (10785-1, proteintech, 1:500), PCNA (SC-56, Santa, 1:500), $\beta$-actin (AP0060, Bioworld, USA; $1: 10,000)$, in dilution buffer for one night at $4^{\circ} \mathrm{C}$. After three times (every $10 \mathrm{~min}$ ) washes in Tris-bufferedsaline with Tween (TBST), membranes were incubated with goat anti-rabbit horseradish peroxidase (HRP)conjugated secondary antibodies (Bioworld, USA; $1: 10,000)$ in dilution buffer for $2 \mathrm{~h}$ at room temperature. After three times (every $10 \mathrm{~min}$ ) washes, bands were visualized by enhanced chemiluminescence's (ECL) using the LumiClo substrate (Super SignalWest Pico Trial Kit, Pierce, USA), signals were recorded and analyzed respectively by an imaging system (Bio-Rad, USA) and
Quantity One software (Bio-Rad, USA). Values of protein were presented as fold change relative to the average value of CON group.

\section{MiRNAs expression assay}

Total RNA (2 ug) treated with RNase-free DNase I (Promega, USA) were polyadenylated by poly(A) polymerase using a poly(A) tailing kit (AM1350; Applied Biosystems), according to the manufacturer's instructions. Polyadenylated RNA was then dissolved and reverse transcribed using a poly(T) adapter. Realtime PCR was performed with SYBR Green qPCR master mix reagent (Takara) in triplicate using a microRNA (miRNA)specific forward primer and a universal reverse primer complementary to part of the poly $(\mathrm{T})$ adapter sequence.U6 small-nuclear RNA (U6 snRNA) was used as a reference gene to normalise the expression of miRNA [38]. The sequences of all porcine miRNA were acquired from miRBase (http://www.mirbase.org/). miRNA targeting CYP27A1were predicted with an online miRNA prediction tool [39]. Among all the predicted miRNA, eleven targeting CYP27A1were quantified by real-time PCR. The primer sequences used for miRNA analysis are listed in Table 3.

\section{Co-transfections and dual luciferase activity assay}

The pmirGLO-CYP27A1-3'UTR vector was constructed, by inserting CYP27A1 3'UTR with the putative binding site of miR-1608 and site of miR-1699 at the downstream of the

Table 3: miRNA and the corresponding primer sequences

\begin{tabular}{llc}
\hline Names & Primer sequences & miRbase Accession \\
\hline gga-miR-1699 & CCAGAGGGACATGGCAGGGCAA & MIMAT0007591 \\
gga-miR-1777 & GTGGGCGGTGCGGGGCGGCG & MIMAT0007688 \\
gga-miR-103-3p & AGCAGCATTGTACAGGGCTATGA & MIMAT0001145 \\
gga-miR-1454 & GTACAATGATGAGACTTTGGCTCC & MIMAT0007331 \\
gga-miR-6651-5p & ACCAGGTTGCCTAAGGAGGGG & MIMAT0025751 \\
gga-miR-1464 & TGCTGTTTGCAGGGCCGCCTCGGA & MIMAT0007342 \\
gga-miR-1563 & GCACATGATGAGGAAGCACTGAAA & MIMAT0007422 \\
gga-miR-7477-5p & ACAGCGCGGATCGGGGCTGGGAG & MIMAT0029108 \\
gga-miR-1451-5p & TCGCACAGGAGCAAGTTACCGC & MIMAT0007324 \\
gga-miR-7475-5p & CCGCCGCCGCCGCGCCCTCC & MIMAT0029104 \\
gga-miR-1608 & TGGGACAGTGGCTGCGCCCTCT & MIMAT0007474 \\
universal reverse primer & TAGAGTGAGTGTAGCGAGCA & N/A \\
poly(T) adapter & TAGAGTGAGTGTAGCGAGCACAGA & N/A \\
U6 & ATTAATACGACTCACTATAGG(T)16VN & \\
\hline
\end{tabular}


firefly luciferase gene into pmir vector (Promega). Plasmids were prepared with E.Z.N.A. ${ }^{\text {TM }}$ Endo-free Plasmid Maxi Kit (Omega Bio-tek). HeLa cells $\left(1 \times 10^{5}\right.$ cells per well) were seeded in a 24-well culture plate and cultured with DMEM medium with 10\% fetal bovine serum (FBS). As the confluence of HeLa cells reached $80-90 \%$, pmirGLO vector (174 ng) and pmirGLO-CYP27A1-3'UTR vector (174 ng) were transfected into HeLa cells simultaneously with $100 \mathrm{nM}$ miRNA mimics via Lipofectamine 2000TM (Invitrogen). Twenty-four hours and forty-eight hours later, the luciferase activity was detected according to the manufacturer's instruction using the luciferase reporter assay system (GloMax® 96 Microplate Luminometer; Promega), and the relative luciferase activity value showed as FL/RL that was achieved from the firefly luciferase activity by the Renilla luciferase as control per sample. The normalized relative luciferase activity of different groups was used for statistical analysis.

\section{Statistical analysis}

Data are presented as means \pm SEM. The data were tested for normal distribution, and statistical significance was assessed by Student's unpaired test using the software package SPSS version 18.0 for Windows (SPSS Inc., Chicago, IL, USA). Data were considered statistically significant when $\mathrm{P}<0.05$.

\section{ACKNOWLEDGMENTS}

This work was supported by the Special Fund for Agro-scientific Research in the Public Interest (201003011), the Fundamental Research Funds for the Central Universities (KYZ201212) and the Priority Academic Program Development of Jiangsu Higher Education Institutions (PAPD).

\section{CONFLICTS OF INTEREST}

The authors have no conflicts of interest to declare.

\section{REFERENCES}

1. Radtke F and Clevers H. Self-renewal and cancer of the gut: Two sides of a coin. Science. 2005; 307:1904-1909.

2. Fiocchi C. Inflammatory bowel disease: etiology and pathogenesis. Gastroenterology. 1998; 115:182-205.

3. Adams C, Vahl HA and Veldman A. Interaction between nutrition and Eimeria acervulina infection in broiler chickens: Development of an experimental infection model. Brit J Nutr. 1996; 75:867-873.

4. Witlock DR and Ruff MD. Comparison of the intestinal surface damage caused by Eimeria mivati, E. necatrix, E. maxima, E. brunetti, and E. acervulina by scanning electron microscopy. The Journal of parasitology. 1977; 63:193-199.
5. Swaggerty CL, Genovese KJ, He H, Duke SE, Pevzner IY and Kogut MH. Broiler breeders with an efficient innate immune response are more resistant to Eimeria tenella. Poultry Sci. 2011; 90:1014-1019.

6. Tan JZ, Applegate TJ, Liu SS, Guo YM and Eicher SD. Supplemental dietary L-arginine attenuates intestinal mucosal disruption during a coccidial vaccine challenge in broiler chickens. Brit J Nutr. 2014; 112:1098-1109.

7. Paris NE and Wong EA. Expression of digestive enzymes and nutrient transporters in the intestine of Eimeria maximainfected chickens. Poultry Sci. 2013; 92:1331-1335.

8. Su S, Miska KB, Fetterer RH, Jenkins MC and Wong EA. Expression of digestive enzymes and nutrient transporters in Eimeria acervulina-challenged layers and broilers. Poultry Sci. 2014; 93:1217-1226.

9. Dinarello CA. Inflammation in Human Disease: Anticytokine Therapy. Biol Blood Marrow Tr. 2009; 15:134-136.

10. Zaki MH, Lamkanfi $M$ and Kanneganti TD. The Nlrp3 inflammasome: contributions to intestinal homeostasis. Trends in immunology. 2011; 32:171-179.

11. Makishima M, Okamoto AY, Repa JJ, Tu H, Learned RM, Luk A, Hull MV, Lustig KD, Mangelsdorf DJ and Shan B. Identification of a nuclear receptor for bile acids. Science. 1999; 284:1362-1365.

12. Faust PL and Kovacs WJ. Cholesterol biosynthesis and ER stress in peroxisome deficiency. Biochimie. 2014; 98:75-85.

13. Kruit JK, Groen AK, van Berkel TJ and Kuipers F. Emerging roles of the intestine in control of cholesterol metabolism. World J Gastroenterol. 2006; 12:6429-6439.

14. Hu Y, Sun Q, Li X, Wang M, Cai D and Li X. In Ovo Injection of Betaine Affects Hepatic Cholesterol Metabolism through Epigenetic Gene Regulation in Newly Hatched Chicks (vol 10, e0122643, 2015). Plos One. 2015; 10.

15. Chiang JY. Regulation of bile acid synthesis. Frontiers in bioscience : a journal and virtual library. 1998; 3:d176-193.

16. Russell DW. The enzymes, regulation, and genetics of bile acid synthesis. Annual review of biochemistry. 2003; 72:137-174.

17. Soto-Acosta R, Mosso C, Cervantes-Salazar M, PuertaGuardo H, Medina F, Favari L, Ludert JE and Angel RM. The increase in cholesterol levels at early stages after dengue virus infection. correlates with an augment in LDL particle uptake and HMG-CoA reductase activity. Virology. 2013; 442:132-147.

18. Kettunen H, Tiihonen K, Peuranen S, Saarinen MT and Remus JC. Dietary betaine accumulates in the liver and intestinal tissue and stabilizes the intestinal epithelial structure in healthy and coccidia-infected broiler chicks. Comparative Biochemistry and Physiology a-Molecular and Integrative Physiology. 2001; 130:759-769.

19. Perez-Carbajal C, Caldwell D, Farnell M, Stringfellow K, Pohl S, Casco G, Pro-Martinez A and Ruiz-Feria CA. Immune response of broiler chickens fed different levels of 
arginine and vitamin $\mathrm{E}$ to a coccidiosis vaccine and Eimeria challenge. Poultry Sci. 2010; 89:1870-1877.

20. Michael E and Hodges RD. Scanning electron microscopy of the duodenal mucosa of chickens infected with Eimeria acervulina. Parasitology. 1975; 71:229-237.

21. Ruff MD, Witlock DR and Smith RR. Eimeria acervulina and E. tenella:effect on methionine absorption by the avian intestine. Experimental parasitology. 1976; 39:244-251.

22. Peek HW and Landman WJ. Coccidiosis in poultry: anticoccidial products, vaccines and other prevention strategies. The Veterinary quarterly. 2011; 31:143-161.

23. Uni Z, Platin R and Sklan D. Cell proliferation in chicken intestinal epithelium occurs both in the crypt and along the villus. J Comp Physiol B. 1998; 168:241-247.

24. Uni Z, Geyra A, Ben-Hur H and Sklan D. Small intestinal development in the young chick: crypt formation and enterocyte proliferation and migration. Brit Poultry Sci. 2000; 41:544-551.

25. Maekawa S, Sato C, Kitajima K, Funatsu N, Kumanogoh $\mathrm{H}$ and Sokawa Y. Cholesterol-dependent localization of NAP-22 on a neuronal membrane microdomain (raft). The Journal of biological chemistry. 1999; 274:21369-21374.

26. Parpal S, Karlsson M, Thorn H and Stralfors P. Cholesterol depletion disrupts caveolae and insulin receptor signaling for metabolic control via insulin receptor substrate-1, but not for mitogen-activated protein kinase control. The Journal of biological chemistry. 2001; 276:9670-9678.

27. Stange EF, Preclik G, Schneider A and Reimann F. The Role of Enterocyte Cholesterol-Metabolism in IntestinalCell Growth and Differentiation. Scand J Gastroentero. 1988; 23:79-85.

28. Duan YJ, Fu WY, Wang S, Ni YD and Zhao RQ. Effects of tonic immobility (TI) and corticosterone (CORT) on energy status and protein metabolism in pectoralis major muscle of broiler chickens. Comp Biochem Phys A. 2014; 169:90-95.

29. Monte MJ, Marin JJG, Antelo A and Vazquez-Tato J. Bile acids: Chemistry, physiology, and pathophysiology. World J Gastroentero. 2009; 15:804-816.
30. Gonzalez FJ. Nuclear Receptor Control of Enterohepatic Circulation. Compr Physiol. 2012; 2:2811-2828.

31. Li TG, Chen WL and Chiang JYL. PXR induces CYP27A1 and regulates cholesterol metabolism in the intestine. Journal of lipid research. 2007; 48:373-384.

32. Cai D, Jia Y, Lu J, Yuan M, Sui S, Song H and Zhao R. Maternal dietary betaine supplementation modifies hepatic expression of cholesterol metabolic genes via epigenetic mechanisms in newborn piglets. The British journal of nutrition. 2014; 112:1459-1468.

33. Brisbin JT, Gong $\mathrm{J}$ and Sharif S. Interactions between commensal bacteria and the gut-associated immune system of the chicken. Animal health research reviews / Conference of Research Workers in Animal Diseases. 2008; 9:101-110.

34. Allen PC and Wong HYC. Effect of Atherogenic Diet on Chicken Plasma-Lipids and Lipoproteins. Poultry Sci. 1993; 72:1673-1678.

35. Yue C, Ma BQ, Zhao YZ, Li QR and Li JS. Lipopolysaccharide-Induced Bacterial Translocation Is Intestine Site-Specific and Associates with Intestinal Mucosal Inflammation. Inflammation. 2012; 35:1880-1888.

36. Liu ZZ, Xi J, Schroder S, Wang WG, Xie TP, Wang ZG, Bao SS and Fei J. Chimonanthus nitens var. salicifolius Aqueous Extract Protects against 5-Fluorouracil Induced Gastrointestinal Mucositis in a Mouse Model. Evid-Based Compl Alt. 2013.

37. Troche C, Eicher SD and Applegate TJ. The influence of dietary zinc source and coccidial vaccine exposure on intracellular zinc homeostasis and immune status in broiler chickens. Brit J Nutr. 2015; 114:202-212.

38. Cai D, Yuan M, Jia Y, Liu H, Hu Y and Zhao R. Maternal gestational betaine supplementation-mediated suppression of hepatic cyclin D2 and presenilin1 gene in newborn piglets is associated with epigenetic regulation of the STAT3-dependent pathway. The Journal of nutritional biochemistry. 2015.

39. Kertesz M, Iovino N, Unnerstall U, Gaul U and Segal E. The role of site accessibility in microRNA target recognition. Nat Genet. 2007; 39:1278-1284. 